\title{
Biomaterial-based platforms for in situ dendritic cell programming and their use in antitumor immunotherapy
}

\author{
João Calmeiro ${ }^{1,2}$, Mylène Carrascal ${ }^{2,3}$, Célia Gomes ${ }^{4,5}$, Amílcar Falcão $^{1,6}$, Maria Teresa Cruz ${ }^{1,2}$ and \\ Bruno Miguel Neves ${ }^{7^{*}}$ (i)
}

\begin{abstract}
Dendritic cells (DCs) are central players in the immune system, with an exquisite capacity to initiate and modulate immune responses. These functional characteristics have led to intense research on the development of DC-based immunotherapies, particularly for oncologic diseases. During recent decades, DC-based vaccines have generated very promising results in animal studies, and more than 300 clinical assays have demonstrated the safety profile of this approach. However, clinical data are inconsistent, and clear evidence of meaningful efficacy is still lacking. One of the reasons for this lack of evidence is the limited functional abilities of the used ex vivo-differentiated DCs. Therefore, alternative approaches for targeting and modulating endogenous DC subpopulations have emerged as an attractive concept. Here, we sought to revise the evolution of several strategies for the in situ mobilization and modulation of DCs. The first approaches using chemokine-secreting irradiated tumor cells are addressed, and special attention is given to the cutting-edge injectable bioengineered platforms, programmed to release chemoattractants, tumor antigens and DC maturating agents. Finally, we discuss how our increasing knowledge of DC biology, the use of neoantigens and their combination with immune checkpoint inhibitors can leverage the refinement of these polymeric vaccines to boost their antitumor efficacy.
\end{abstract}

Keywords: Biomaterial-based scaffolds, Dendritic cells, In situ mobilization, Antitumor immunotherapy

\section{Dendritic cell-based approaches in antitumor immunotherapy}

Approaches to enhance or restore the immune system aptitude to identify and destroy malignant cells have long been viewed as a central goal in cancer treatment [1-3]. The use of dendritic cells (DCs), powerful modulators of immune responses, in immunotherapy has been extensively scrutinized and has been highly desirable for clinical application since the early 1990s. There are more than 300 completed or ongoing registered clinical trials using these cells as antitumor vaccines [4]. Currently, there are mainly two approaches for exploring DCs in oncologic treatments: 1) vaccines constituted by ex vivogenerated DCs matured and loaded with tumor antigens and 2) in vivo direct targeting of antigens to DCs [5].

\footnotetext{
* Correspondence: bruno.neves@ua.pt

${ }^{7}$ Department of Medical Sciences and Institute of Biomedicine - iBiMED, University of Aveiro, Agra do Crasto - Edifício 30, 3810-193 Aveiro, Portugal Full list of author information is available at the end of the article
}

Manipulation of DCs ex vivo followed by their injection back into the patient is the most common approach, which is being used in $97 \%$ of referenced clinical trials [4]. In this approach, blood precursors $\left(\mathrm{CD} 14^{+}\right.$monocytes or $\mathrm{CD} 4^{+}$hematopoietic stem cells) are collected from patients, differentiated into DCs, loaded with antigens and matured. The resultant cellular product is cryopreserved and then released for administration according to the defined vaccination schedule.

These types of vaccines present exceptional tolerability, but the procedure is highly expensive and laborious as result of the required manipulation in GMP conditions and notwithstanding the good safety profile, the rate of success is inconsistent [4]. In fact, objective tumor responses using standard oncologic criteria are usually low, with reports ranging from 3.3 to $15 \%$ [6-8]. Furthermore, promising vaccines in early phase studies [9-12] often fail to present clear beneficial clinical outputs in phase III trials [13]. So far, only sipuleucel-T, 
an autologous antigen-presenting cell vaccine for the treatment of asymptomatic metastatic hormone refractory prostate cancer, has demonstrated satisfactory efficacy in phase III trials and was approved by the Food and Drug Administration (FDA) in 2010. The lack of robustness of $\mathrm{DC}$-antitumor immunotherapies was attributed in part to low numbers of injected cells that are able to migrate to the lymph nodes and to prime $\mathrm{T}$ lymphocytes $[14,15]$ and also to functional limitations of the ex vivo-differentiated DCs. These DCs, which are differentiated from hematopoietic precursors, have been shown to be less efficient than endogenous DC subpopulations, specifically in their competence to cross-present antigens to $\mathrm{CD}^{+} \mathrm{T}$ cells $[16,17]$. The lack of definition of immunogenic neoantigens, the use of shared antigens, the induction of low levels of $\mathrm{CD}^{+} \mathrm{T}$ cell responses and the inexistence of standardized production and manufacturing protocols are other reasons to explain the poor efficacy of DC vaccines.

To overcome the limitations of ex vivo manipulated DC vaccines, several strategies aiming to directly target antigens to endogenous DCs have been developed in recent years $[18,19]$. These strategies encompass antigen coupling to monoclonal antibodies specific to DC surface molecules, including XCR1, DCIR, Cleac9A, CD40, DC-SIGN DEC-205 and the mannose receptor. Preclinical and clinical studies demonstrated encouraging results, with the establishment of effective antitumor $\mathrm{CD} 8^{+}$and $\mathrm{CD} 4^{+} \mathrm{T}$ cell responses and humoral immunity [20-28]. However, clinical implementation has been struggling with several challenges: the approach demands the co-administration of DC maturation agents; otherwise, it is prone to induce tolerance to the vehiculated antigen [29]; it is limited to immunization with one known tumor antigen at a time; and the targeted receptor needs to be unequivocally expressed by the selected DC subpopulation.

Another way to explore the immunogenic power of endogenous DC populations in cancer therapies relies on strategies for their in situ mobilization and modulation. They consist of implantable or injectable biomaterialbased scaffolds providing a specific microenvironment that allows the recruitment of desired DC populations and potentiates their interaction with other immune effectors. Seminal and promising applications of this approach, which encompass both biotechnology and immunology, have gradually appeared in the cancer immunotherapy field and will be the focus of the present review.

\section{Strategies for in situ DC mobilization and antigen loading \\ GM-CSF-secreting tumor cells}

One of the first approaches used for in situ mobilization and activation of endogenous DCs was the use of irradiated tumor cells that were genetically altered to secrete cytokines/chemokines [30, 31]. Among these strategies, GM-CSF-secreting tumor cell vaccines attracted particular interest [32]. GM-CSF is a hematopoietic cytokine with multiple effects on the immune system: it directly influences hematopoiesis and expansion of granulocytes, macrophages, DCs, eosinophils and neutrophils [33, 34] and indirectly modulates $\mathrm{T}$ cell activation and proliferation [35]. In the context of DC-based antitumor vaccines, GM-CSF is particularly appealing, given that it is a powerful DC chemoattractant and a maturation inducer [36-38]. Furthermore, GM-CSF also presents immuneindependent effects by directly inhibiting cancer cell proliferation $[39,40]$.

Seminal studies by Glenn Dranoff and colleagues, performed with the B16 melanoma mouse model, demonstrated that intradermal injection of irradiated GM-CSF-secreting tumor cells efficiently induces strong, specific and prolonged antitumor immunity [30]. The main action of the approach is due to the generation of a local inflammatory reaction with recruitment and activation of DCs, macrophages and granulocytes [30, 41-43]. Briefly, GM-CSF secreted by modified tumor cells attracts DCs to the injection site. Recruited DCs engulf apoptotic tumor cells and mature via the effect of released GM-CSF. Then, mature DCs migrate to draining lymph nodes to efficiently present processed tumor antigens to $\mathrm{T}$ cells, resulting in lymphocyte activation and expansion with the consequent boost of the antitumor immune response. Clinically, several phase I/II clinical trials exploring this type of vaccine have shown a coherent induction of humoral and cellular immunity in several cancers, such as melanoma [44, 45]; pancreatic [46-48], prostate $[49,50]$, kidney [51] cancer; and chronic myeloid leukemia [52].

However, these vaccines present some drawbacks. The sustained GM-CSF release by injected tumor cells can paradoxically lead to disease progression due to the provocation of immune tolerance via the differentiation of tolerogenic DCs and the recruitment of myeloid suppressor cells [53-55]. Moreover, clinical trial outcomes are often variable, with tumor regressions being inconsistent within patients and with phase III trials that continuously failed $[32,56]$. Hence, despite initial promising results, the GVAX vaccine - a whole cell pancreatic cancer vaccine plus GM-CSF-expressing tumor cells - failed due to lack of efficacy [57]. However, we are currently in an exciting era of scientific achievements in cancer immunotherapy, supported by a growing knowledge on the precise interactions of tumors and the different immune players. Thus, new vaccine designs accommodating this information and exploring novel biotechnological solutions are required and highly anticipated. 


\section{Biomaterial-based platforms for DC recruitment and antigen loading}

Biomaterial-based nanosized delivery systems, including polymeric nanoparticles, dendrimers and liposomes, have long been viewed as a valuable approach to enhance antitumor immunity (reviewed in [58]). These nanoparticles carry immunomodulatory agents and tumor antigens and, after capture by host DCs, elicit strong immune responses. $[59,60]$. In a preclinical context, the approach was efficient for some types of cancer; however, clinical translation faces several challenges. There is some risk of offtarget effects, systemic cytotoxicity, problems related to stability, cargo bioavailability and long-term efficacy.

In 2002, Tadashi Kumamoto and collaborators conceived a novel strategy to modulate endogenous DCs envisaging a specific immune response. They resorted to subcutaneous implantation of a biomaterial-based scaffold designed to release DC chemoattractants alongside the tumor lysate [61]. Endogenous DCs are recruited to the scaffold where they are fueled and activated by released antigens and maturating agents, respectively. The rationale is similar to using tumor cells modified to release chemokines; however, it allows for the precise control of the release of chemoattractants, antigens and maturation inducers. Furthermore, these $3 \mathrm{D}$ matrices work as platforms that favor the interaction between DCs and additional immune cells, such as $\mathrm{T}$ and NK cells (Fig. 1).

In the last decade, this concept of biomaterial-based DC programming systems has gained significant relevance, with the emergence of two different strategies: two-step or one-step approaches, depending on the time of loading of antigens (Table 1).

\section{Two-step approach}

In the seminal work of Tadashi Kumamoto, ethylenevinyl-acetate (EVA) polymer rods releasing chemokine (C-C motif) ligand 19 (CCL19) were subcutaneously implanted in the abdominal skin of mice [61]. More than $70 \%$ of the chemokine was released in a fully functional form in the first $48 \mathrm{~h}$. This resulted in the recruitment and transitory entrapment of Langerhans cells (LCs), a particular subset of skin DCs, into the scaffold. Antigen loading was achieved in a second step by the (co)implantation of EVA rods carrying tumor lysates, defined MHC I-restricted peptides or artificial xenogeneic antigens. To trigger maturation and LC migration from the epidermis to draining lymph nodes, haptens such as DNFB or oxazolone were applied over the implantation sites. The strategy was as effective as conventional ex vivo DC vaccines in eliciting tumor-specific Cytotoxic T-lymphocyte (CTL) activities. Moreover, the authors demonstrated the efficacy of the approach in fibrosarcoma, E. G7-OVA tumor and Lewis lung carcinoma mouse models, both in a prophylactic (implantation of rods before tumor inoculation) and therapeutic (implantation of rods after tumor inoculation) context [61].

Following a similar strategy, a novel and more advanced two-step approach based on hydrogel matrices

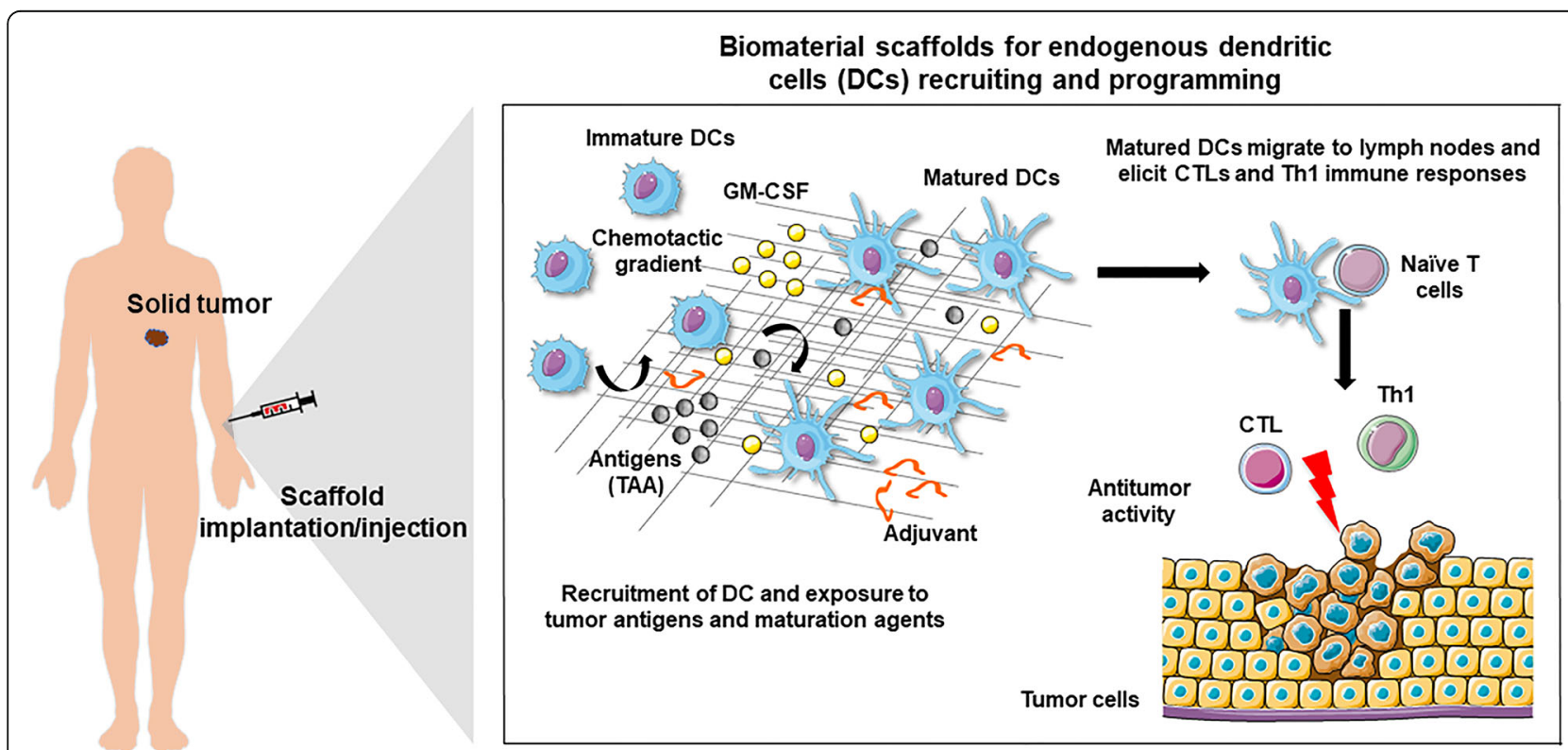

Fig. 1 Biomaterial-based scaffold application in DC recruitment and programming for enhanced antitumor activity. A subcutaneously implanted or injected biocompatible polymer scaffold is designed to include and release, in a controlled way, a DC chemotactic agent, an adjuvant, and a source of tumor antigens. The loaded chemoattractant, e.g., GM-CSF, recruits immature dendritic cells (iDCs) into the macroporous matrix where they are exposed to adjuvants and tumor antigens. Mature antigen-loaded DCs (matured DCs) then migrate out of the scaffold to the lymph nodes, presenting processed antigens to T-cells, and boosting antitumor immunity that way 
Table 1 Overview of different existing anti-cancer biomaterial-based vaccines for DC recruitment and antigen loading

\begin{tabular}{|c|c|c|c|c|}
\hline Approach & Scaffold biomaterial & Load & Administration & Target/tumor model \\
\hline \multirow[t]{2}{*}{ Two step } & $\begin{array}{l}\text { Ethylene-vinyl-acetate } \\
\text { (EVA) polymers rods }\end{array}$ & $\begin{array}{l}\text { 1st CCL19 } \\
\text { 2nd Tumor lysate }\end{array}$ & Coimplantation & $\begin{array}{l}\text { E.G7-OVA tumor cells } \\
\text { injected mice [61] }\end{array}$ \\
\hline & $\begin{array}{l}\text { Hydrogel - Thermosensitive } \\
\text { monomethoxypoly(ethylene glycol)- } \\
\text { co-poly(lactic-co-glycolic acid) } \\
\text { copolymer (mPEG-PLGA) }\end{array}$ & $\begin{array}{l}\text { 1st - GM-CSF } \\
\text { 2nd - Tumor antigens }\end{array}$ & $\begin{array}{l}2 \text { injections } \\
\text { (injection of viral or nonviral } \\
\text { vectors in a 2nd step) }\end{array}$ & $\begin{array}{l}\text { Murine melanoma } \\
\text { model [62] }\end{array}$ \\
\hline \multirow[t]{15}{*}{ One step } & Poly(lactide-co-glycolide) & $\begin{array}{l}\text { GM-CSF, CpG, autologous } \\
\text { tumor lysate }\end{array}$ & Implantation & $\begin{array}{l}\text { Human melanoma } \\
\text { Phase I clinical trial } \\
\text { NCT01753089 }\end{array}$ \\
\hline & Poly(lactide-co-glycolide) & GM-CSF, CpG, tumor lysate & Implantation & $\begin{array}{l}\text { Murine melanoma } \\
\text { model }[41,63-66]\end{array}$ \\
\hline & Poly(lactide-co-glycolide) & GM-CSF, CpG, tumor lysate & Implantation & $\begin{array}{l}\text { Murine Lewis lung } \\
\text { carcinoma (LLC) [64] }\end{array}$ \\
\hline & Poly(lactide-co-glycolide) & GM-CSF, CpG, tumor lysate & Implantation & $\begin{array}{l}\text { Rat glioma } \\
\text { model }[67,68]\end{array}$ \\
\hline & Poly(lactide-co-glycolide) & GM-CSF, CpG, Tumor lysate & Implantation & $\begin{array}{l}\text { Murine melanoma } \\
\text { model; combination } \\
\text { with anti PD-1 or } \\
\text { CTLA-4 mAb [69] }\end{array}$ \\
\hline & Poly(lactide-co-glycolide) & CCL20, CpG, tumor lysate & Implantation & $\begin{array}{l}\text { Murine melanoma } \\
\text { model [66] }\end{array}$ \\
\hline & Poly(lactide-co-glycolide) & Flt3L, CpG, tumor lysate & Implantation & $\begin{array}{l}\text { Murine melanoma } \\
\text { model [66] }\end{array}$ \\
\hline & Poly(lactide-co-glycolide) & GM-CSF, MPLA, tumor lysate & Implantation & $\begin{array}{l}\text { Murine melanoma } \\
\text { model [64] }\end{array}$ \\
\hline & Poly(lactide-co-glycolide) & GM-CSF, Poly-I:C, Tumor lysate & Implantation & $\begin{array}{l}\text { Murine melanoma } \\
\text { model [64] }\end{array}$ \\
\hline & Poly(lactide-co-glycolide) & GM-CSF, Poly-l:C, tumor lysate & Implantation & $\begin{array}{l}\text { Murine Lewis lung } \\
\text { carcinoma (LLC) [64] }\end{array}$ \\
\hline & Hydrogel/cryogel-alginate polymer & $\begin{array}{l}\text { GM-CSF, CpG, irradiated } \\
\text { tumor cells }\end{array}$ & Injection & $\begin{array}{l}\text { Murine breast } \\
\text { cancer [70] }\end{array}$ \\
\hline & Hydrogel/cryogel-alginate polymer & $\begin{array}{l}\text { GM-CSF, CpG, irradiated } \\
\text { tumor cells }\end{array}$ & Injection & $\begin{array}{l}\text { Murine melanoma } \\
\text { model [71] }\end{array}$ \\
\hline & $\begin{array}{l}\text { Covalent and ionic crosslinked } \\
\text { cryogel-alginate polymer }\end{array}$ & $\begin{array}{l}\text { GM-CSF, CpG, irradiated } \\
\text {-tumor cells }\end{array}$ & Injection & $\begin{array}{l}\text { Murine breast } \\
\text { cancer [72] }\end{array}$ \\
\hline & $\begin{array}{l}\text { Crosslinking hydrogel- dextran } \\
\text { vinylsulfone and tetra-thiolated } \\
\text { polyethyleneglycol }\end{array}$ & $\begin{array}{l}\text { CCL20 + PLGA microparticles } \\
\text { encapsulating IL-10, } \\
\text { siRNA and DNA antigen }\end{array}$ & Injection & $\begin{array}{l}\text { Murine A20 B cell } \\
\text { lymphoma [73] }\end{array}$ \\
\hline & $\begin{array}{l}\text { Mesoporous silica rods (MSRs) - } \\
\text { synthetic amorphous silica }\end{array}$ & GM-CSF, CpG, OVA & Injection & $\begin{array}{l}\text { Prophylactic action in } \\
\text { a murine model, } \\
\text { injected with EG7- } \\
\text { OVA lymphoma } \\
\text { cells [74] }\end{array}$ \\
\hline
\end{tabular}

was developed [62]. First, DCs are attracted to an injectable thermosensitive monomethoxypoly(ethylene glycol)-co-poly(lactic-co-glycolic acid) copolymer (mPEGPLGA) hydrogel via continuous and controlled release of GM-CSF $[62,75]$. In a second phase, viral and nonviral vectors were used to deliver cancer antigens and to program recruited DCs. The hydrogel scaffold was able to release GM-CSF and recruit DCs and macrophages. This strategy resulted in the production of strong tumorspecific immune responses in therapeutic and prophylactic settings of murine melanoma models [62].

\section{One-step approach}

\section{Implantable structures}

As an evolution of the two-step system, in the last decade, David Mooney and collaborators conceived several biomaterial-based implantable or injectable platforms for endogenous DC recruitment and antigen loading, all in a single step. Biocompatible polymers were designed to include and release, in a controlled way, a DC chemotactic agent, adjuvants and tumor antigens [63]. Several of these approaches are based on an extremely porous scaffold composed of poly(lactide-coglycolide) (PLG). 
PLG has multiple applications in the biomedical field owing to its specific characteristics: FDA approved for clinical use, prone to surface modification to enhance biological interactions, high biocompatibility and tailorable biodegradation rate [76].

Using a high-pressure $\mathrm{CO}_{2}$ foaming process, GM-CSF was encapsulated into macroporous PLG matrices with efficiencies above $50 \%[77,78]$. These scaffolds release up to $60 \%$ of loaded GM-CSF during the initial 5 days, with the remaining gradually released during an additional 10 days [63]. To strongly activate recruited DCs, CpGoligonucleotides (CpG-ODN) were also immobilized to the matrices. For this, CpG-ODNs were condensed with polyethylenimine to form cationic nanoparticles that electrostatically interact with the anionic PLG biomaterial, resulting in a retention higher than $80 \%$ over 25 days [63]. The scaffolds containing GM-CSF, melanoma tumor lysates and CpGODN were assayed in the syngeneic B16-F10 murine melanoma model across several works. The structures were able to attract and activate several DC subsets $\left(\mathrm{CD} 11 \mathrm{c}^{+}\right.$, pDCs and $\mathrm{CD}^{+} \mathrm{DCs}$ ) for at least 2 weeks [65]. Importantly, the number of DCs accumulated in the scaffold was of the same magnitude as that commonly administered in ex vivogenerated DC protocols [63]. Vaccination with these 3D macroporous structures elicited robust tumor-specific CTL responses promoting complete tumor regression in $47 \%$ of mice [41], 50\% survival in a therapeutic goal, $33 \%$ in a longterm survival goal and a notable $90 \%$ in a prophylactic goal $[63,64]$.

In subsequent studies, PLG matrices were used to supply other chemokines, such as CCL20 and Flt3L, or other adjuvants, such as MPLA and Poly-I:C, ligands for TLR4 and TLR3, respectively [64, 66]. Disregarding the adjuvant used, vaccine efficacy was shown to highly correlate to the quantities of recruited $\mathrm{CD}^{+}$and $\mathrm{pDCs}$ alongside local GM-CSF and IL-12p70 concentrations [64]. PLG scaffolds were also tested in combination with monoclonal antibodies, targeting the immune checkpoints programmed cell death ligand 1 (PD-L1) and cytotoxic Tlymphocyte antigen 4 (CTLA-4). These combinations elicited strong CTL activity and tumor regression, reaching a remarkable $75 \%$ survival rate in murine models of melanoma [69]. Finally, in addition to these successful tests in preclinical melanoma models, DC-recruiting and programming PLG scaffolds also showed therapeutic activity in rat glioma models [67, 68] and mouse lung carcinoma [64].

The translation of this approach to the clinical context is presently being evaluated in a phase I clinical trial (NCT01753089) for the treatment of stage IV metastatic melanoma. It is an open-label interventional study designed to address the safety and feasibility of developing and implanting DC activating scaffolds incorporating autologous melanoma cell lysates in patients with metastatic melanoma. Additionally, as secondary objectives, the study aims to address the immune response, tumor regression and survival. This vaccine, named WDVAX, is composed of PLGA polymer and includes clinical grade GM-CSF, autologous tumor cell lysate and CpGODN as a DC maturation agent. The structure is implanted surgically on the patient's arm, leg or torso by cutting a small incision into the skin and sliding it into the "pocket" created between the upper layer of the skin and the tissue underneath.

Regarding the clinical trial structure, enrollment consists of 23 patients who will receive 4 scaffolds by implantation, with skin biopsy being performed after the last vaccine. The study is divided into 3 cohorts of 3-5 patients, with each one being evaluated in a dose escalation schema, based upon the intervals between scaffold implantation at separate sites: in cohort 1 , the devices are implanted monthly; in cohort 2, the implantation is performed every 3 weeks; in cohort 3 , the procedure changes every 2 weeks. CT scan and/or MRI exams are performed to assess the tumor at 3 time points: before the vaccine procedure starts, halfway through the vaccination schedule and 1 month after completion of all 4 vaccines. Finally, the exam will be repeated every 3 months after the end of the protocol. The clinical study is ongoing, with results expected to be out in 2020 .

\section{Injectable structures}

The concept of DC-recruiting structures was then expanded to other biomaterials, such as hydrogels [70, 71, 73, 79-81], mesoporous silica rods (MSRs) [74] and gelatin [82]. Hydrogel scaffolds have been applied in the biomedical field aimed at cell encapsulation in tissue engineering [83] and for controlled and sustained delivery of drugs [84-87], including therapeutic peptide and proteins [88]. Regarding DC programing platforms, hydrogel-based scaffolds offer the advantage of being deliverable through conventional needle-syringe injection, minimizing the risks and invasiveness associated with surgically implantable structures. Alginate or gelatin hydrogels developed for this purpose are normally obtained by cryogelation [80, 82]. This technique allows for the development of cryogels with considerably larger interconnected pores [89-93] and augmented mechanical stability [90] when compared to hydrogels obtained by other approaches. Briefly, the reactants are limited to the unfrozen/ semi-frozen phases, forming a crosslinked network after polymerization. The ice crystals nucleated in the aqueous phase throughout freezing form pores as they melt, creating interconnected macroporous networks. Alginate cryogel produced pore sizes of $150-200 \mu \mathrm{m}$, high connectivity of pores, and shape-memory. These characteristics allow them to regain initial dimensions without considerable deformation after injection. Moreover, the open pore structure 
confers tissue-like elasticity and creates a favorable microenvironment for cell infiltration. When loaded with GMCSF, these alginate cryogels were reported to present an encapsulation efficiency of $89 \%$, with $80 \%$ of the total encapsulated cytokine being released within 3 days and a complete release attained after 4 weeks [80].

These scaffolds were preclinically tested as vaccines in several types of cancer. In mouse breast cancer models, injection of a matrix comprising live attenuated HER-2/ neu-overexpressing breast cancer cells, GM-CSF and CpGODN resulted in the recruitment and activation of DCs followed by a robust antitumor response. The vaccine resulted in $100 \%$ survival in vaccinated mice and in a 70 fold enhancement in antibody production when compared to untreated mice [70]. In another work, alginate cryogels loaded with irradiated tumor cells and encapsulating and releasing CpG-ODN and GM-CSF in a controlled manner were tested in a mouse melanoma model (Fig. 2) [71]. This vaccine efficiently stimulated the recruitment and activation of $\mathrm{CD}^{+} \mathrm{DCs}, \mathrm{CD} 11^{+} \mathrm{DCs}$ and pDCs. Hence, prophylactic and therapeutic protection against cancer was tested and confirmed. Specifically, potent antigen-specific $\mathrm{T}$ cell responses were detected, conferring long-term prophylactic protection against melanoma. With this regimen, $80 \%$ of mice survived, and importantly, of these, $100 \%$ survived a second challenge with tumor cells, indicating the induction of strong immunologic memory. When tested in a therapeutic context, two vaccination doses at days 3 and 10 post tumor establishment with B16-F10 cells strikingly resulted in complete regression of tumors in $40 \%$ of the animals [71]. Recently, the injectability of these cryogels was improved by a combination of ionic and covalent crosslinking [72]. The new scaffolds are tougher and allow for the use of a small caliber needle with no damage after injection. These improved cryogels were shown to avoid tumor development in $80 \%$ of mice injected with HER2/neu-overexpressing breast cancer cells [72].

In situ crosslinking hydrogels formed via Michael type addition of dextran vinylsulfone and tetra-thiolated polyethylene glycol were also tested as DC programming platforms [81]. These synthetic immune priming centers were loaded with CCL20 and PLGA microparticles carrying IL10 siRNA and plasmid DNA antigen. They were shown to degrade within 2 to 7 days and to release the chemokine in a sustained manner, which resulted in up to 8-fold more DCs attracted in vivo compared to blank hydrogels [73]. Recruited DCs phagocytose microparticles and mature as observed by strong expression of CD40 and CD86. The prophylactic efficacy of these platforms was examined in mice challenged with lymphoma cells. After three immunizations separated by 14 days, animals were inoculated with lethal doses of A20-tumor cells and survived until all negative control group mice (PBS-injected) died. Vaccination resulted in a substantial enhancement in both parameters:
43 days median survival and $40 \%$ survival in immunized mice vs 32 days median survival and $0 \%$ survival in PBS group. The effect was attributed to DC-induced stimulation of potent Th1 and CTL antitumor responses [73].

MSRs are another type of biomaterial that has been tested as the core of DC programming scaffold vaccines [74]. Synthetic amorphous silica is characterized by great biocompatibility $[94,95]$ and safety [96] and, due to high pore volume and wide surface area, is frequently used as a carrier in controlled drug release devices [97, 98]. The DC programming scaffolds based on MSRs are synthesized with a specific hexagonal mesoporous structure via a silica sol-gel reaction in the presence of pore-directing agents [99-101]. The formed nanopores provide a high surface area for payload adsorption and surface modification [74, 102]. These MSRs spontaneously assemble in situ after injection, forming configurations with interparticle spaces that allow cell infiltration [74]. In in vitro studies, MSRs loaded with ovalbumin (OVA), CpG-ODN and GM-CSF demonstrated continuous release of the cytokine and of the TLR3 agonist during long periods. In vivo, the scaffolds increased the persistence of OVA antigen when compared to a soluble bolus and recruited large

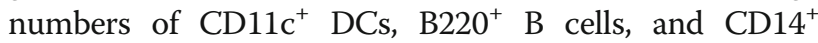
monocytes to the site of injection [74]. The vaccine induced potent Th1 and Th2 immune responses and antigen-specific $\mathrm{CD}^{+} \mathrm{T}$ cells, causing a significant tumor growth delay in mice subcutaneously challenged with EG7-OVA lymphoma cells [74]. The physicochemical properties of MSRs render these platforms highly tunable through modification of surface chemistry. Accordingly, diverse poly(ethylene glycol) (PEG) modifications were shown to considerably augment DC maturation and in vitro production of IL-1 $\beta$ as well as to boost innate immune cell infiltration in vivo [102].

\section{Future perspectives and concluding remarks}

In recent years, biomaterial-based injectable or implantable scaffolds designed to recruit provide antigens and maturation signals to endogenous DCs have emerged as an exciting and elegant approach to elicit antitumor responses. These biomaterial-based DC programming platforms presented very promising preclinical results against several types of cancer, and the technology is expected to transition to the clinic. Accordingly, this approach is now being tested in a phase I trial in metastatic melanoma patients (WDVAX vaccine, trial NCT01753089).

The next challenge in this field will be the design of scaffolds to recruit specific DC subpopulations with superior cross-priming abilities, such as Langerhans cells and cDC1 cells $\left(\mathrm{CD} 141^{+}\right.$CLEC9A + XCR1 $\left.{ }^{+}\right)$[103-105]. This would be achievable by loading the structures with more selective chemotactic agents: CX3CL1, CCL2 and CCL7 for Langerhans cells or XCL1/XCL2 for cDC1. 

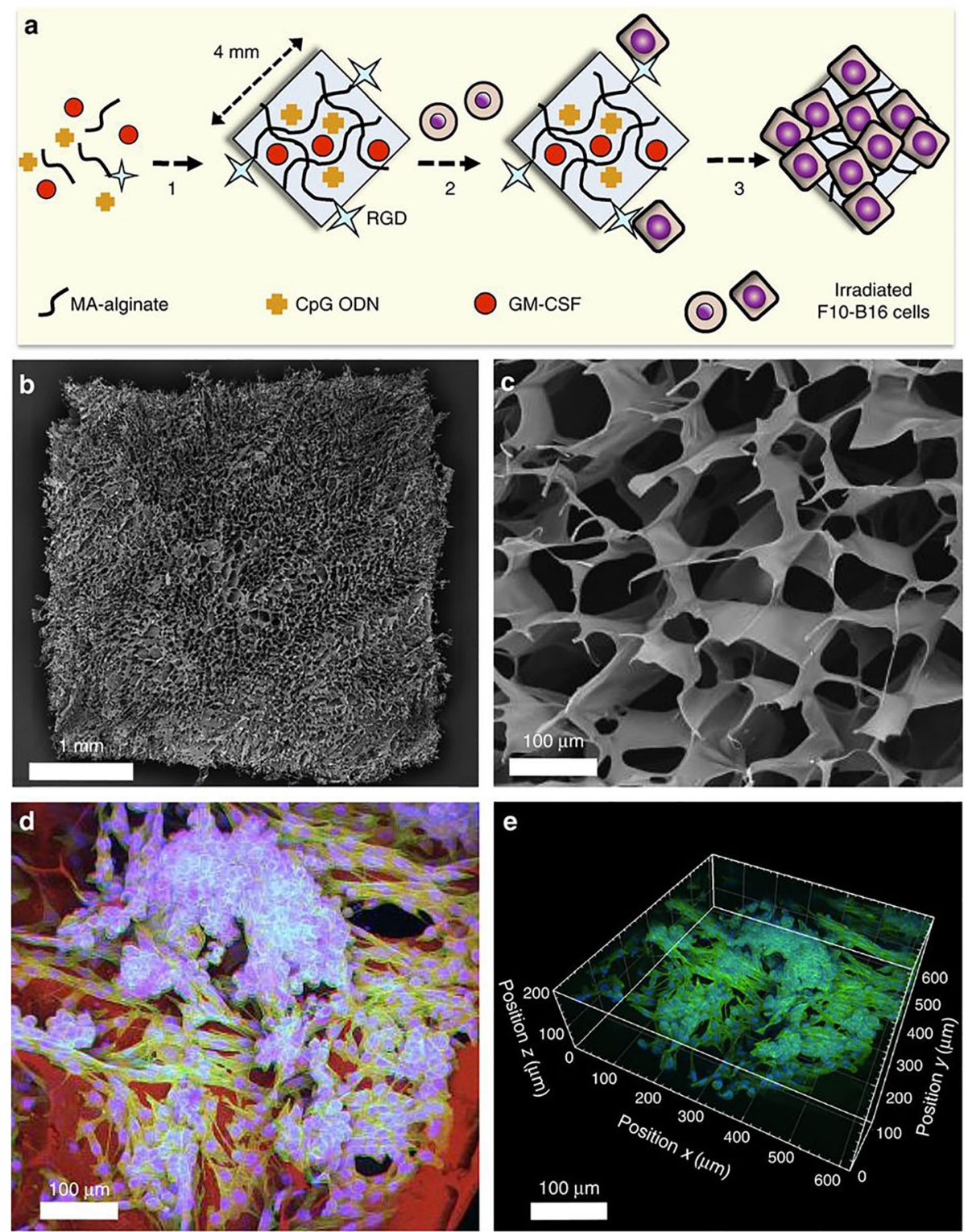

Fig. 2 Fabrication and imaging of irradiated tumor cell-loaded cryogel sponge vaccines. a Preparation of an alginate-derived active vaccine containing viable irradiated B16-F10 cells for the treatment of melanoma in syngeneic C57BL/6 mice. CpG ODN (TLR9-based immune adjuvant) and GM-CSF (cytokine adjuvant)-loaded RGD-containing alginate cryogels were prepared by a cryogelation process at subzero temperature. The gels were subsequently seeded with irradiated B16-F10 melanoma cells (depicted as round-shaped cells) and incubated for $6 \mathrm{~h}$ (depicted as square-shaped spread cells) before animal vaccination via subcutaneous injection. b SEM showing homogeneous macroporous microstructure throughout the square-shaped sponge-like gel construct. c SEM cross-sectional image of an alginate cryogel showing the interconnected macroporous network. $\mathbf{d}$ 2D confocal micrograph displaying immobilization of irradiated B16-F10 cells on a typical RGD-containing cryogel after $6 \mathrm{~h}$ culture. Actin filaments in cells were visualized by staining with Alexa Fluor 488-phalloidin (green), cell nuclei were stained with DAPI (blue), and polymer walls were stained with polylysine-labeled rhodamine (red). e 3D reconstructed confocal fluorescence micrograph of irradiated B16F10 cells in cryogel, depicting cell adhesion, spreading and elongation after $6 \mathrm{~h}$ culture. Reproduced with permission from Springer Nature, reference [71] https://www.nature.com/articles/ncomms8556 Copyright 2015

The cDC1 subpopulation, apart from its exquisite crosspresenting capacity, is of particular interest because it was shown to produce, upon TLR3 engagement, IL12 p70 and IL-15, cytokines with important roles in adequate Th1 polarization and CTL and NK cell activation [106]. Moreover, given that the XCR1 ligands are selectively expressed in $\mathrm{NK}$ and $\mathrm{CD}^{+} \mathrm{T}$ cells, the crosstalk of these cells with $\mathrm{cDC} 1$ is facilitated, which is expected to result in superior antitumor immunity [107]. In fact, several preclinical studies have demonstrated that targeting antigens to $\mathrm{Xcr} 1^{+} \mathrm{CD} 8 \alpha$ DCs (mice equivalent to human $\mathrm{cDC} 1$ ) induces strong and potent 
antitumor responses $[108,109]$. The fast-growing field of biomaterials continuously provides new technological advances, allowing the establishment of more efficient and controllable long-term release of the selected chemotactic agents. A clear example of this is the recent development of injectable lactic/glycolic copolymer microparticles functioning as pulsatile drug-delivery systems with controlled release from a few days up to 2 months [110].

Another highly desirable improvement for this vaccine technology is the loading of DCs with neoantigens encompassing individual patient tumor mutational heterogeneity. Identifying and targeting patient-specific neoantigens is considered a key feature for the development of nextgeneration immunotherapies [111-113]. Two seminal studies demonstrated the feasibility, safety, and immunogenicity of vaccines consisting of direct injection of melanoma-related neoantigens, either as mRNA (NCT02035956) [114] or as synthetic long peptides (NCT01970358) [115]. These works paved the way in this highly promising area, currently with more than 70 clinical trials testing neoantigen immunization. However, the definition of an optimal delivery strategy to target neoantigens to professional antigen-presenting cells to elicit potent antitumor CTL responses remains a challenge [116]. Recently, neo-epitopeloaded DCs were tested in a small phase I trial carried out on patients with advanced melanoma (NCT00683670). This vaccination approach consisted of autologous ex vivodifferentiated DCs loaded with gp100-derived peptides and seven patient-specific neoantigens. The study reported a robust induction of neoantigen-specific $\mathrm{CD}^{+} \mathrm{T}$ cells as early as 2 weeks after vaccination and the detection of memory $\mathrm{T}$ cells up to 4 months after the final dose [117].

Regarding biomaterial-assisted delivery of neoantigens, the existing data are extremely promising, although still only coming from preclinical studies. In one of these works, synthetic high density lipoprotein (sHDL) nanodiscs were shown to markedly improve neoantigen/CpG co-delivery to lymphoid organs and to sustain antigen presentation on DCs [118]. When tested in a murine MC38 colon carcinoma model, the sHDL structures generated a 47 -fold greater frequency of neoantigen-specific CTLs when compared with the soluble neoantigen $+\mathrm{CpG}$ immunization. This resulted in substantially slowed tumor growth and, when combined with anti PD-1 treatment, led to complete tumor regression in $88 \%$ of tested mice, compared with only $25 \%$ observed in the soluble neoantigen $+\mathrm{CpG}+$ anti $\mathrm{PD}-1$ treated group [118]. In another exciting work, self-assembled intertwining DNA-RNA nanocapsules (iDR-NCs) were shown to efficiently deliver CpGs, Stat3 short hairpin RNA, and the MC38 tumor neoantigen Adpgk into APCs. Immunization of C57BL/6 mice with iDR-NC/Adpgk nanovaccines elicited an 8-fold increase in specific CTLs relative to soluble CpG + Adpgk, induced immunological memory and significantly inhibited the progression of colorectal tumors [119]. Finally, mesoporous silica micro-rods combined with polyethyleneimine (PEI), the MSR-PEI vaccine, were also recently tested as a platform for neoantigen delivery [120]. A single immunization with MSR-PEI containing a pool of B16F10 or CT26 neoantigens significantly increased IFNy ${ }^{+}, \mathrm{TNFa}^{+}$ and Granzyme $\mathrm{B}^{+}$TILs. Furthermore, the vaccine controlled tumor growth and eradicated established lung metastases of respective tumors, synergizing with anti-CTLA4 therapy.

The combination of biomaterials-based platforms for in situ programming of DCs with other immunotherapies is also expected to contribute to more robust and effective antitumor immune responses. Due to their clear clinical effectiveness, immune checkpoint inhibitors are promising candidates for these associations $[121,122]$. These combinatory therapeutic regimens will tackle multiple aspects of the tumor immunoediting process: the vaccine boosts the elimination phase by eliciting and expanding effector immune cells, while checkpoint inhibitors block major tumor escape mechanisms. In fact, numerous clinical trials focused on DC vaccines targeting cancer are currently testing their association with checkpoint inhibitors [123]. Interestingly, while sipuleucel- $\mathrm{T}$ presented moderate clinical outputs as a monotherapy, early observations from recent trials investigating its combination with atezolizumab (AntiPD-L1) (NCT03024216) or ipilimumab (NCT01804465) show very promising results [124]. Hence, it is also expected that the number of studies exploring the combination of biomaterial-based DC programming vaccines with immune checkpoint inhibitors, such as PDL-1, PD-1 and CTLA-4 mAbs, will strongly increase in the next few years. Indeed, PLG scaffolds combined with anti CTLA-4 or anti PD-1 antibodies were already tested and reported to elicit strong CTL activity and tumor elimination in murine models of melanoma [69]. Follow-up studies of this strategy for a consequent translation to clinical trials are needed, allowing the development of novel and more thrilling paths in cancer immunotherapy.

\footnotetext{
Abbreviations

APC: Antigen-presenting cell;; CAR: Chimeric antigen receptor; CCL19: Chemokine ligand 19; CDC1: Conventional type 1 dendritic cells; CpGODN: CpG oligonucleotide; CT: Computed tomography; CTL: Cytotoxic Tlymphocyte; CTLA-4: Cytotoxic T-lymphocyte antigen 4; CXCR3: Chemokine receptor CXCR3; DC: Dendritic cell; EVA: Ethylene-vinyl-acetate; FDA: Food and drug administration; GM-CSF: Granulocyte-macrophage colonystimulating factor; GMP: Good manufacturing practices; HLA: Human leucocyte antigens; IFN- $\gamma$ : Interferon gamma; IL: Interleukin; LC: Langerhans cell; LLC: Lewis lung carcinoma; mAb: Monoclonal antibody; MHC: Major histocompatibility complex; mPEG-PLGA: monomethoxypoly(ethylene glycol)-co-poly(lactic-co-glycolic acid); MPLA: Monophosphoryl lipid A; MRI: Magnetic resonance imaging; MSR: Mesoporous silica rod; NK: Natural killer; OVA: Ovalbumin; PBMCs: Peripheral blood mononuclear cells; PDC: plasmacytoid dendritic cell; PD-L1: Programmed cell death ligand 1; PEG: Poly(ethylene glycol); PLG: Poly(lactide-co-glycolide); PolyI:C: Polyinosinic:polycytidylic acid; TAA: Tumor-associated antigens; Th1: T
} 
helper cell type 1; Th2: T helper cell type 2; TIL: Tumor-infiltrating lymphocytes; TLR: Toll-like receptor; TNF: Tumor necrosis factor

\section{Acknowledgements}

Not applicable

\section{Authors' contributions}

$J C$ and $M C$ performed the literature search and wrote the first draft of the manuscript. CG, AF, MTC and BMN revised and edited the final version of the manuscript. All authors read and approved the final manuscript.

\section{Funding}

This work was financially supported by the Portuguese Science and Technology Foundation (FCT), European Regional Development Fund (FEDER) Competitiveness and Internationalization Operational Program (COMPETE2020) and own Revenues of the University of Coimbra, project POCI-01-0247-FEDER-033532. Thanks are due to FCT/FEDER/COMPETE2020 to the financial support to iBiMED (UID/BIM/04501/2013 and UID/BIM/04501/ 2019). João Calmeiro is supported by the FCT through an individual PhD fellowship (PD/BDE/135076/2017).

\section{Availability of data and materials}

Not applicable.

\section{Ethics approval and consent to participate}

Not applicable.

\section{Consent for publication}

Not applicable.

\section{Competing interests}

The authors declare that they have no competing interests.

\section{Author details \\ ${ }^{1}$ Faculty of Pharmacy, University of Coimbra, 3000-548 Coimbra, Portugal. ${ }^{2}$ Center for Neuroscience and Cell Biology, University of Coimbra, 3004-504 Coimbra, Portugal. ${ }^{3}$ Tecnimede Group, Sintra, Portugal. ${ }^{4}$ Coimbra Institute for Clinical and Biomedical Research, Faculty of Medicine, University of Coimbra, Coimbra, Portugal. ${ }^{5}$ Center for Innovation in Biomedicine and Biotechnology, University of Coimbra, Coimbra, Portugal. ${ }^{6}$ Coimbra Institute for Biomedical Imaging and Translational Research (CIBIT), University of Coimbra, Coimbra, Portugal. 'Department of Medical Sciences and Institute of Biomedicine - iBiMED, University of Aveiro, Agra do Crasto - Edifício 30, 3810-193 Aveiro, Portugal.}

\section{Received: 24 October 2018 Accepted: 23 August 2019}

\section{Published online: 04 September 2019}

\section{References}

1. Oettgen HF. Immunotherapy of cancer. N Engl J Med. 1977;297:484-91.

2. Ngwa W, Irabor OC, Schoenfeld JD, Hesser J, Demaria S, Formenti SC. Using immunotherapy to boost the abscopal effect. Nat Rev Cancer. 2018;18:31322.

3. Martin-Liberal J, Ochoa de Olza M, Hierro C, Gros A, Rodon J, Tabernero J. The expanding role of immunotherapy. Cancer Treat Rev. 2017:54:74-86.

4. Constantino J, Gomes C, Falcão A, Cruz MT, Neves BM. Antitumor dendritic cell-based vaccines: lessons from 20 years of clinical trials and future perspectives. Transl Res. 2016;168:74-95.

5. Palucka K, Banchereau J. Dendritic-cell-based therapeutic cancer vaccines. Immunity. 2013;39:38-48

6. Klebanoff CA, Acquavella N, Yu Z, Restifo NP. Therapeutic cancer vaccines: are we there yet? Immunol Rev. 2011;239:27.

7. Rosenberg SA, Yang JC, Restifo NP. Cancer immunotherapy: moving beyond current vaccines. Nat Med. 2004;10:909-15.

8. Anguille S, Smits EL, Lion E, van Tendeloo VF, Berneman ZN. Clinical use of dendritic cells for cancer therapy. Lancet Oncol. 2014;15:e257-67.

9. Vansteenkiste J, Zielinski M, Linder A, Dahabreh J, Gonzalez EE, Malinowski W, et al. Adjuvant MAGE-A3 immunotherapy in resected non-small-cell lung Cancer: phase II randomized study results. J Clin Oncol. 2013;31:2396-403.

10. Kruit WHJ, Suciu S, Dreno B, Mortier L, Robert C, Chiarion-Sileni V, et al. Selection of Immunostimulant AS15 for active immunization with MAGE-A3 protein: results of a randomized phase II study of the European Organisation for Research and Treatment of Cancer melanoma Group in Metastatic Melanoma. J Clin Oncol. 2013;31:2413-20.

11. Butts C, Maksymiuk A, Goss G, Soulières D, Marshall E, Cormier Y, et al. Updated survival analysis in patients with stage IIIB or IV non-small-cell lung cancer receiving BLP25 liposome vaccine (L-BLP25): phase IIB randomized, multicenter, open-label trial. J Cancer Res Clin Oncol. 2011;137:1337-42.

12. Butts C, Socinski MA, Mitchell PL, Thatcher N, Havel L, Krzakowski M, et al. Tecemotide (L-BLP25) versus placebo after chemoradiotherapy for stage III non-small-cell lung cancer (START): a randomised, double-blind, phase 3 trial. Lancet Oncol. 2014;15:59-68.

13. Okamoto M, Kobayashi M, Yonemitsu Y, Koido S, Homma S. Dendritic cellbased vaccine for pancreatic cancer in Japan. World J Gastrointest Pharmacol Ther. 2016;7:133.

14. Verdijk P, Aarntzen EHJG, Lesterhuis WJ, Boullart ACl, Kok E, van Rossum $\mathrm{MM}$, et al. Limited amounts of dendritic cells migrate into the T-cell area of lymph nodes but have high immune activating potential in melanoma patients. Clin Cancer Res. 2009;15:2531-40.

15. Fong L, Brockstedt D, Benike C, Wu L, Engleman EG. Dendritic cells injected via different routes induce immunity in cancer patients. J Immunol. 2001;166:4254-9.

16. Romano E, Rossi M, Ratzinger G, de Cos M-A, Chung DJ, Panageas KS, et al. Peptide-loaded Langerhans cells, despite increased IL15 secretion and T-cell activation in vitro, elicit antitumor T-cell responses comparable to peptide-loaded monocyte-derived dendritic cells in vivo. Clin Cancer Res. 2011;17:1984-97.

17. Ratzinger G, Baggers J, de Cos MA, Yuan J, Dao T, Reagan JL, et al. Mature human Langerhans cells derived from CD34+ hematopoietic progenitors stimulate greater cytolytic T lymphocyte activity in the absence of bioactive IL-12p70, by either single peptide presentation or cross-priming, than do dermal-interstitial or monoc. J Immunol. 2004;173:2780-91.

18. Gilboa E. DC-based cancer vaccines. J Clin Invest. 2007;117:1195-203.

19. Steinman RM, Banchereau J. Taking dendritic cells into medicine. Nature. 2007:449:419-26.

20. Caminschi I, Maraskovsky E, Heath WR. Targeting dendritic cells in vivo for Cancer therapy. Front Immunol. 2012;3:13.

21. Cohn L, Delamarre L. Dendritic cell-targeted vaccines. Front Immunol. 2014:5:255.

22. Bonifaz LC, Bonnyay DP, Charalambous A, Darguste DI, Fujii S-I, Soares H, et al. In vivo targeting of antigens to maturing dendritic cells via the DEC205 receptor improves T cell vaccination. J Exp Med. 2004;199:815-24.

23. Kastenmüller W, Kastenmüller K, Kurts C, Seder RA. Dendritic cell-targeted vaccines - hope or hype? Nat Rev Immunol. 2014;14:705-11.

24. Kretz-Rommel A, Qin F, Dakappagari N, Torensma R, Faas S, Wu D, et al. In vivo targeting of antigens to human dendritic cells through DC-SIGN elicits stimulatory immune responses and inhibits tumor growth in grafted mouse models. J Immunother. 2007:30:715-26.

25. Tullett KM, Leal Rojas IM, Minoda Y, Tan PS, Zhang J-G, Smith C, et al. Targeting CLEC9A delivers antigen to human CD141(+) DC for CD4(+) and CD8(+)T cell recognition. JCl insight. 2016;1:e87102.

26. Chatterjee B, Smed-Sorensen A, Cohn L, Chalouni C, Vandlen R, Lee B-C, et al. Internalization and endosomal degradation of receptor-bound antigens regulate the efficiency of cross presentation by human dendritic cells. Blood. 2012;120:2011-20.

27. Tel J, Sittig SP, Blom RAM, Cruz LJ, Schreibelt G, Figdor CG, et al. Targeting uptake receptors on human Plasmacytoid dendritic cells triggers antigen cross-presentation and robust type I IFN secretion. J Immunol. 2013;191:5005-12.

28. Tel J, Benitez-Ribas D, Hoosemans S, Cambi A, Adema GJ, Figdor CG, et al. DEC-205 mediates antigen uptake and presentation by both resting and activated human plasmacytoid dendritic cells. Eur J Immunol. 2011;41:1014-23.

29. Bonifaz L, Bonnyay D, Mahnke K, Rivera M, Nussenzweig MC, Steinman RM. Efficient targeting of protein antigen to the dendritic cell receptor DEC-205 in the steady state leads to antigen presentation on major histocompatibility complex class I products and peripheral CD8+ T cell tolerance. J Exp Med. 2002;196:1627-38.

30. Dranoff G, Jaffee E, Lazenby A, Golumbek P, Levitsky H, Brose K, et al. Vaccination with irradiated tumor cells engineered to secrete murine granulocyte-macrophage colony-stimulating factor stimulates potent, specific, and long-lasting anti-tumor immunity. Proc Natl Acad Sci U S A. 1993;90:3539-43. 
31. Mach N, Dranoff G. Cytokine-secreting tumor cell vaccines. Curr Opin Immunol. 2000;12:571-5.

32. Yan W-L, Shen K-Y, Tien C-Y, Chen Y-A, Liu S-J. Recent progress in GM-CSFbased cancer immunotherapy. Immunotherapy. 2017;9:347-60.

33. Metcalf D. The colony-stimulating factors and cancer. Nat Rev Cancer. 2010; 10:425-34.

34. Metcalf D. Hematopoietic cytokines. Blood. 2008;111:485-91.

35. Hercus TR, Thomas $D$, Guthridge MA, Ekert PG, King-Scott J, Parker $M W$, et al. The granulocyte-macrophage colony-stimulating factor receptor: linking its structure to cell signaling and its role in disease. Blood. 2009;114:1289-98.

36. Bhattacharya P, Haddad C, Alharshawi K, Prabhakar B. The role of GM-CSF in dendritic cell development in vivo (HEM3P.284). J Immunol. 2014;192(1 Supplement):51.13.

37. Zhan Y, Vega-Ramos J, Carrington EM, Villadangos JA, Lew AM, Xu Y. The inflammatory cytokine, GM-CSF, alters the developmental outcome of murine dendritic cells. Eur J Immunol. 2012:42:2889-900.

38. van de Laar L, Coffer PJ, Woltman AM. Regulation of dendritic cell development by GM-CSF: molecular control and implications for immune homeostasis and therapy. Blood. 2012;1 19:3383-93.

39. Yamashita Y, Nara N, Aoki N. Antiproliferative and differentiative effect of granulocyte-macrophage colony-stimulating factor on a variant human small cell lung cancer cell line. Cancer Res. 1989;49:5334-8.

40. Urdinguio RG, Fernandez AF, Moncada-Pazos A, Huidobro C, Rodriguez RM, Ferrero C, et al. Immune-dependent and independent antitumor activity of GM-CSF aberrantly expressed by mouse and human colorectal tumors. Cancer Res. 2013;73:395-405.

41. Ali OA, Emerich D, Dranoff G, Mooney DJ. In Situ Regulation of DC Subsets and T Cells Mediates Tumor Regression in Mice. Sci Transl Med. 2009;1:8ra19.

42. Zarei S, Schwenter F, Luy P, Aurrand-Lions M, Morel P, Kopf M, et al. Role of GM-CSF signaling in cell-based tumor immunization. Blood. 2009;113:6658-68.

43. Mach N, Gillessen S, Wilson SB, Sheehan C, Mihm M, Dranoff G. Differences in dendritic cells stimulated in vivo by tumors engineered to secrete granulocyte-macrophage Colony-stimulating factor or Flt3-ligand 1. Cancer Res. 2000;60:3239-46.

44. Lipson EJ, Sharfman WH, Chen S, McMiller TL, Pritchard TS, Salas JT, et al. Safety and immunologic correlates of melanoma GVAX, a GM-CSF secreting allogeneic melanoma cell vaccine administered in the adjuvant setting. J Transl Med. 2015;13:214.

45. Kusumoto M, Umeda S, Ikubo A, Aoki Y, Tawfik O, Oben R, et al. Phase 1 clinical trial of irradiated autologous melanoma cells adenovirally transduced with human GM-CSF gene. Cancer Immunol Immunother. 2001;50:373-81.

46. Lutz ER, Wu AA, Bigelow E, Sharma R, Mo G, Soares K, et al. Immunotherapy converts nonimmunogenic pancreatic tumors into immunogenic foci of immune regulation. Cancer Immunol Res. 2014;2:616-31.

47. Laheru D, Lutz E, Burke J, Biedrzycki B, Solt S, Onners B, et al. Allogeneic granulocyte macrophage Colony-stimulating factor-secreting tumor immunotherapy alone or in sequence with cyclophosphamide for metastatic pancreatic Cancer: a pilot study of safety, feasibility, and immune activation. Clin Cancer Res. 2008;14:1455-63.

48. Lutz E, Yeo CJ, Lillemoe KD, Biedrzycki B, Kobrin B, Herman J, et al. A lethally irradiated allogeneic granulocyte-macrophage colony stimulating factorsecreting tumor vaccine for pancreatic adenocarcinoma. A phase II trial of safety, efficacy, and immune activation. Ann Surg. 2011:253:328-35.

49. Higano CS, Corman JM, Smith DC, Centeno AS, Steidle CP, Gittleman M, et al. Phase 1/2 dose-escalation study of a GM-CSF-secreting, allogeneic, cellular immunotherapy for metastatic hormone-refractory prostate cancer. Cancer. 2008;113:975-84.

50. Le DT, Pardoll DM, Jaffee EM. Cellular vaccine approaches. Cancer J. 2010;16:304-10.

51. Tani K, Azuma M, Nakazaki Y, Oyaizu N, Hase H, Ohata J, et al. Phase I study of autologous tumor vaccines transduced with the GM-CSF gene in four patients with stage IV renal cell Cancer in Japan: clinical and immunological findings. Mol Ther. 2004;10:799-816.

52. Smith BD, Kasamon YL, Kowalski J, Gocke C, Murphy K, Miller CB, et al. K562/ GM-CSF immunotherapy reduces tumor burden in chronic myeloid leukemia patients with residual disease on imatinib mesylate. Clin Cancer Res. 2010;16:338-47.

53. Filipazzi P, Valenti $R$, Huber V, Pilla $L$, Canese $P$, lero M, et al. Identification of a new subset of myeloid suppressor cells in peripheral blood of melanoma patients with modulation by a granulocyte-macrophage colony-stimulation factor-based antitumor vaccine. J Clin Oncol. 2007:25:2546-53.

54. Sica A, Bronte V. Altered macrophage differentiation and immune dysfunction in tumor development. J Clin Invest. 2007;117:1155-66.

55. Jinushi M, Tahara H. Cytokine gene-mediated immunotherapy: current status and future perspectives. Cancer Sci. 2009;100:1389-96.

56. Melero I, Gaudernack G, Gerritsen W, Huber C, Parmiani G, Scholl S, et al. Therapeutic vaccines for cancer: an overview of clinical trials. Nat Rev Clin Oncol. 2014;11:509-24

57. Arlen PM, Mohebtash M, Madan RA, Gulley JL. Promising novel immunotherapies and combinations for prostate cancer. Future Oncol. 2009:5:187-96.

58. Zang X, Zhao X, Hu H, Qiao M, Deng Y, Chen D. Nanoparticles for tumor immunotherapy. Eur J Pharm Biopharm. 2017;115:243-56.

59. Diwan M, Tafaghodi M, Samuel J. Enhancement of immune responses by co-delivery of a CpG oligodeoxynucleotide and tetanus toxoid in biodegradable nanospheres. J Control Release. 2002;85:247-62.

60. Clawson C, Huang C-T, Futalan D, Martin Seible D, Saenz R, Larsson M, et al. Delivery of a peptide via poly(d,l-lactic-co-glycolic) acid nanoparticles enhances its dendritic cell-stimulatory capacity. Nanomed Nanotechnol Biol Med. 2010:6:651-61.

61. Kumamoto T, Huang EK, Paek HJ, Morita A, Matsue H, Valentini RF, et al. Induction of tumor-specific protective immunity by in situ Langerhans cell vaccine. Nat Biotechnol. 2002;20:64-9.

62. Liu Y, Xiao L, Joo K-I, Hu B, Fang J, Wang P. In situ modulation of dendritic cells by injectable thermosensitive hydrogels for cancer vaccines in mice. Biomacromolecules. 2014;15:3836-45.

63. Ali OA, Huebsch N, Cao L, Dranoff G, Mooney DJ. Infection-mimicking materials to program dendritic cells in situ. Nat Mater. 2009:8:151-8,

64. Ali OA, Verbeke C, Johnson C, Sands RW, Lewin SA, White D, et al. Identification of immune factors regulating antitumor immunity using polymeric vaccines with multiple adjuvants. Cancer Res. 2014;74:1670-81.

65. Ali OA, Doherty E, Mooney DJ, Emerich D. Relationship of vaccine efficacy to the kinetics of DC and T-cell responses induced by PLG-based cancer vaccines. Biomatter. 2011;1:66-75

66. Ali OA, Tayalia P, Shvartsman D, Lewin S, Mooney DJ. Inflammatory cytokines presented from polymer matrices differentially generate and activate DCs in situ. Adv Funct Mater. 2013:23:4621-8.

67. Ali OA, Doherty E, Bell WJ, Fradet T, Hudak J, Laliberte M-T, et al. Biomaterial-based vaccine induces regression of established intracranial glioma in rats. Pharm Res. 2011;28:1074-80.

68. Ali OA, Doherty E, Bell WJ, Fradet T, Hudak J, Laliberte M-T, et al. The efficacy of intracranial PLG-based vaccines is dependent on direct implantation into brain tissue. J Control Release. 2011;154:249-57.

69. Ali OA, Lewin SA, Dranoff G, Mooney DJ. Vaccines combined with immune checkpoint antibodies promote cytotoxic T-cell activity and tumor eradication. Cancer Immunol Res. 2016:4:95-100.

70. Bencherif S, Draganov D, Lewin S, Li A, Sands R, Verbeke C, et al. Immunologically active cryogels for breast cancer therapy (P4329). J Immunol. 2013;190(1 Supplement):126.1.

71. Bencherif SA, Warren Sands R, Ali OA, Li WA, Lewin SA, Braschler TM, et al. Injectable cryogel-based whole-cell cancer vaccines. Nat Commun. 2015;6:7556.

72. Shih T-Y, Blacklow SO, Li AW, Freedman BR, Bencherif S, Koshy ST, et al. Injectable, Tough Alginate Cryogels as Cancer Vaccines. Adv Healthc Mater. 2018;7:1701469.

73. Singh A, Qin $H$, Fernandez I, Wei J, Lin J, Kwak LW, et al. An injectable synthetic immune-priming center mediates efficient T-cell class switching and T-helper 1 response against B cell lymphoma. J Control Release. 2011;155:184-92.

74. Kim J, Li WA, Choi Y, Lewin SA, Verbeke CS, Dranoff G, et al. Injectable, spontaneously assembling, inorganic scaffolds modulate immune cells in vivo and increase vaccine efficacy. Nat Biotechnol. 2014:33:64-72.

75. Peng K-T, Chen C-F, Chu I-M, Li Y-M, Hsu W-H, Hsu RW-W, et al. Treatment of osteomyelitis with teicoplanin-encapsulated biodegradable thermosensitive hydrogel nanoparticles. Biomaterials. 2010:31:5227-36.

76. Gentile P, Chiono V, Carmagnola I, Hatton PV. An overview of poly(lactic-coglycolic) acid (PLGA)-based biomaterials for bone tissue engineering. Int J Mol Sci. 2014;15:3640-59. 
77. Mooney DJ, Baldwin DF, Suh NP, Vacanti JP, Langer R. Novel approach to fabricate porous sponges of poly(D,L-lactic-co-glycolic acid) without the use of organic solvents. Biomaterials. 1996;17:1417-22.

78. Harris LD, Kim BS, Mooney DJ. Open pore biodegradable matrices formed with gas foaming. J Biomed Mater Res. 1998;42:396-402.

79. Hori Y, Winans AM, Huang CC, Horrigan EM, Irvine DJ. Injectable dendritic cell-carrying alginate gels for immunization and immunotherapy. Biomaterials. 2008;29:3671-82.

80. Bencherif SA, Sands RW, Bhatta D, Arany P, Verbeke CS, Edwards DA, et al. Injectable preformed scaffolds with shape-memory properties. Proc Natl Acad Sci U S A. 2012;109:19590-5.

81. Singh A, Suri S, Roy K. In-situ crosslinking hydrogels for combinatorial delivery of chemokines and siRNA-DNA carrying microparticles to dendritic cells. Biomaterials. 2009;30:5187-200.

82. Koshy ST, Ferrante TC, Lewin SA, Mooney DJ. Injectable, porous, and cellresponsive gelatin cryogels. Biomaterials. 2014;35:2477-87.

83. Nicodemus GD, Bryant SJ. Cell encapsulation in biodegradable hydrogels for tissue engineering applications. Tissue Eng Part B Rev. 2008;14:149-65.

84. Kretlow JD, Klouda L, Mikos AG. Injectable matrices and scaffolds for drug delivery in tissue engineering. Adv Drug Deliv Rev. 2007;59:263-73.

85. Todd R, Hoare DSK. Hydrogels in drug delivery: Progress and challenges. Polymer (Guildf). 2008;49:1993-2007.

86. Kulkarni CV, Moinuddin Z, Patil-Sen Y, Littlefield R, Hood M. Lipid-hydrogel films for sustained drug release. Int J Pharm. 2015;479:416-21.

87. Zhu W, Xiong L, Wang $H$, Zha G, Du H, Li X, et al. Sustained drug release from an ultrathin hydrogel film. Polym Chem. 2015;6:7097-9.

88. Vermonden T, Censi R, Hennink WE. Hydrogels for Protein Delivery. Chem Rev. 2012;112:2853-88

89. Hwang Y, Zhang C, Varghese S. Poly(ethylene glycol) cryogels as potential cell scaffolds: effect of polymerization conditions on cryogel microstructure and properties. J Mater Chem. 2010;20:345-51.

90. Lozinsky VI, Galaev IY, Plieva FM, Savina IN, Jungvid H, Mattiasson B. Polymeric cryogels as promising materials of biotechnological interest. Trends Biotechnol. 2003;21:445-51.

91. Henderson TMA, Ladewig K, Haylock DN, McLean KM, O'Connor AJ. Cryogels for biomedical applications. J Mater Chem B. 2013;1:2682.

92. Reichelt S. Introduction to Macroporous Cryogels. Methods Mol Biol. 2015; 1286:173-81.

93. Kumar A, YRSB RM. Cryogels: Freezing unveiled by thawing. Mater Today. 2010;13:42-4.

94. Akbar N, Mohamed T, Whitehead D, Azzawi M. Biocompatibility of amorphous silica nanoparticles: size and charge effect on vascular function, in vitro. Biotechnol Appl Biochem. 2011;58:353-62.

95. Petushkov A, Ndiege N, Salem AK, Larsen S. Toxicity of silica nanomaterials: zeolites, mesoporous silica, and amorphous silica nanoparticles. Adv Mol Toxicol. 2010;4:223-66.

96. Fruijtier-Pölloth C. The safety of nanostructured synthetic amorphous silica (SAS) as a food additive (E 551). Arch Toxicol. 2016;90:2885-916.

97. Xia $\mathrm{T}$, Kovochich $\mathrm{M}$, Liong $\mathrm{M}$, Meng $\mathrm{H}$, Kabehie $\mathrm{S}$, George $\mathrm{S}$, et al. Polyethyleneimine coating enhances the cellular uptake of mesoporous silica nanoparticles and allows safe delivery of siRNA and DNA constructs. ACS Nano. 2009;3:3273-86.

98. Li Z, Barnes JC, Bosoy A, Stoddart JF, Zink JI. Mesoporous silica nanoparticles in biomedical applications. Chem Soc Rev. 2012;41:2590.

99. Schmidt-Winkel P, Yang P, Margolese DI, Chmelka BF, Stucky GD. Fluorideinduced hierarchical ordering of mesoporous silica in aqueous acidsyntheses. Adv Mater. 1999:11:303-7.

100. Sundblom A, Palmqvist AEC, Holmberg K. Study of the Pluronic-silica interaction in synthesis of mesoporous silica under mild acidic conditions. Langmuir. 2010;26:1983-90

101. Marco A, Martines U, Yeong E, André Larbot EP. Temperature dependence in the synthesis of hexagonal MSU-3 type mesoporous silica synthesized with Pluronic P123 block copolymer. Microporous Mesoporous Mater. 2004;74:213-20.

102. Li WA, Lu BY, Gu L, Choi Y, Kim J, Mooney DJ. The effect of surface modification of mesoporous silica micro-rod scaffold on immune cell activation and infiltration. Biomaterials. 2016;83:249-56.

103. Bachem A, Güttler S, Hartung E, Ebstein F, Schaefer M, Tannert A, et al. Superior antigen cross-presentation and XCR1 expression define human CD11c+CD141+ cells as homologues of mouse CD8+ dendritic cells. J Exp Med. 2010;207:1273-81.
104. Flacher V, Sparber F, Tripp CH, Romani N, Stoitzner P. Targeting of epidermal Langerhans cells with antigenic proteins: attempts to harness their properties for immunotherapy. Cancer Immunol Immunother. 2009;58:1137-47.

105. Klechevsky E, Morita R, Liu M, Cao Y, Coquery S, Thompson-Snipes L, et al. Functional specializations of human epidermal Langerhans cells and CD14+ dermal dendritic cells. Immunity. 2008;29:497-510.

106. Cancel J-C, Crozat K, Dalod M, Mattiuz R. Are conventional type 1 dendritic cells critical for protective antitumor immunity and how? Front Immunol. Frontiers. 2019;10:9

107. Dorner BG, Dorner MB, Zhou X, Opitz C, Mora A, Güttler S, et al. Selective expression of the chemokine receptor XCR1 on cross-presenting dendritic cells determines cooperation with CD8+ T cells. Immunity. 2009;31:823-33.

108. Botelho NK, Tschumi BO, Hubbell JA, Swartz MA, Donda A, Romero P. Combination of synthetic long peptides and XCL1 fusion proteins results in superior tumor control. Front Immunol. 2019:10:294.

109. Terhorst D, Fossum E, Baranska A, Tamoutounour S, Malosse C, Garbani M, et al. Laser-assisted intradermal delivery of adjuvant-free vaccines targeting XCR1 ${ }^{+}$dendritic cells induces potent Antitumoral responses. J Immunol. 2015;194:5895-902.

110. McHugh KJ, Nguyen TD, Linehan AR, Yang D, Behrens AM, Rose S, et al. Fabrication of fillable microparticles and other complex 3D microstructures. Science. 2017:357:1138-42.

111. Wang R-F, Wang HY. Immune targets and neoantigens for cancer immunotherapy and precision medicine. Cell Res Publ online 27 December 2016; | doi: 101038/cr2016155. Nat Publ Group; 2016;27:11.

112. McGranahan N, Furness AJS, Rosenthal R, Ramskov S, Lyngaa R, Saini SK, et al. Clonal neoantigens elicit T cell immunoreactivity and sensitivity to immune checkpoint blockade. Science. 2016;351:1463-9.

113. Schumacher TN, Schreiber RD. Neoantigens in cancer immunotherapy. Science. 2015;348:69-74.

114. Sahin U, Derhovanessian E, Miller M, Kloke B-P, Simon P, Löwer M, et al. Personalized RNA mutanome vaccines mobilize poly-specific therapeutic immunity against cancer. Nature. 2017:547:222-6.

115. Ott PA, Hu Z, Keskin DB, Shukla SA, Sun J, Bozym DJ, et al. An immunogenic personal neoantigen vaccine for patients with melanoma. Nature. 2017;547:217-21.

116. Zhu G, Zhang F, Ni Q, Niu G, Chen X. Efficient Nanovaccine delivery in Cancer immunotherapy. ACS Nano. 2017;11:2387-92.

117. Carreno BM, Magrini V, Becker-Hapak M, Kaabinejadian S, Hundal J, Petti AA, et al. A dendritic cell vaccine increases the breadth and diversity of melanoma neoantigen-specific T cells. Science. 2015;348:803-8.

118. Kuai R, Ochyl L, Bahjat KS, Schwendeman A, Moon JJ. Designer vaccine nanodiscs for personalized cancer immunotherapy. Nat Mater. 2017;16:489-98.

119. Zhu G, Mei L, Vishwasrao HD, Jacobson O, Wang Z, Liu Y, et al. Intertwining DNA-RNA nanocapsules loaded with tumor neoantigens as synergistic nanovaccines for cancer immunotherapy. Nat Commun. 2017:8:1482.

120. Li AW, Sobral MC, Badrinath S, Choi Y, Graveline A, Stafford AG, et al. A facile approach to enhance antigen response for personalized cancer vaccination. Nat Mater. 2018;17:528-34.

121. Adachi K, Tamada K. Immune checkpoint blockade opens an avenue of cancer immunotherapy with a potent clinical efficacy. Cancer Sci. 2015;106:945-50

122. Topalian SL, Drake CG, Pardoll DM. Immune checkpoint blockade: a common denominator approach to Cancer therapy. Cancer Cell. 2015 27:450-61.

123. Saxena M, Balan S, Roudko V, Bhardwaj N. Towards superior dendritic-cell vaccines for cancer therapy. Nat Biomed Eng. 2018;2:341-6.

124. Scholz M, Yep S, Chancey M, Kelly C, Chau K, Turner J, et al. Phase I clinical trial of sipuleucel-T combined with escalating doses of ipilimumab in progressive metastatic castrate-resistant prostate cancer. ImmunoTargets Ther. 2017:6:11-6.

\section{Publisher's Note}

Springer Nature remains neutral with regard to jurisdictional claims in published maps and institutional affiliations. 